\section{Systemic Lupus Erythematosus in 6 Male Cocaine Users at Bellevue Hospital}

\section{To the Editor:}

Genetics, environment, and gender contribute to the pathogenesis of systemic lupus erythematosus (SLE). As in other autoimmune diseases, females are more often afflicted than males, with a ratio of 9:1 $1^{1}$. Sex hormones themselves have been held responsible for this imbalance, since SLE often flares during pregnancy and tends to remit after menopause ${ }^{2,3}$.

The effect of cocaine on innate and acquired immunity has been extensively investigated. While cocaine modifies immune responses and is linked to an increased susceptibility to infections ${ }^{4}$, no association between cocaine use and the induction of SLE has been described. We describe 6 cases treated at the New York University Medical Center Bellevue Hospital, an institution often characterized as the "canary in the coal mine" of urban medicine ${ }^{5}$. In this tradition, we describe 6 men with SLE with chronic cocaine abuse and suggest possible mechanisms to explain an association between cocaine and SLE ${ }^{6}$.

Case reports. Patients' characteristics are detailed in Table 1. Patient 1, a 25-year-old Hispanic man with a history of polysubstance abuse, including cocaine, was diagnosed with lupus nephritis that progressed to endstage renal disease despite treatment. Patient 2, a 42-year-old African American man with a history of daily cocaine use, diagnosed with SLE at age 30, presented with Class V+III lupus nephritis and received monthly intravenous (IV) cyclophosphamide, with good response. Patient 3, a 38-year-old Hispanic man with a history of daily cocaine use since age 19, presented acutely ill with pleuropericarditis and renal involvement, progressing to multiorgan failure. He was treated with steroids, plasmapheresis, acute hemodialysis, and monthly IV cyclophosphamide. He achieved remission and is currently off illicit drugs, and has remained clinically and serologically inactive. Patient 4, a 45-year-old African American man with a history of chronic cocaine use, diagnosed with SLE in 2004, is currently clinically inactive and receiving hydroxychloroquine. Patient 5, a 37-year-old African American man with a history of daily cocaine use for 15 years, presented with Class III-V lupus nephritis. He has active renal disease despite the use of mycophenolate mofetil and monthly IV cyclophosphamide. Patient 6, a 31-year-old Hispanic man using cocaine since age 20, was diagnosed with SLE and recently presented with Class IV diffuse proliferative glomerulonephritis and serositis.

None of these patients had a family history of SLE or other autoimmune disease. Interestingly, each had a history of chronic cocaine use, and similar features of SLE such as renal involvement and serositis.

Our report shares the inherent limitations of small-sample case reports and their interpretation. First, we describe 6 cases of SLE in cocaine-abusing men identified within one year. During that period the Bellevue Hospital SLE clinic evaluated 200 patients, of whom 15 were male. Nor do we know the precise incidence of cocaine use in our institution. Galanter, et $a l^{7}$ in 1992 reported a prevalence of 64\% on Bellevue Hospital's general psychiatry wards. Moreover, it is clear that these patients were from similar social background, and from ethnic and/or racial minorities. It would be useful to study a diverse cohort of cocaine users in order to determine whether the association we have reported is greater than chance.

Nevertheless, the relationship between cocaine abuse and the appearance of SLE in men may yield insights into disease pathogenesis. Although sex hormones modify immune responses in women, no relationship between male hormones and SLE has been found. In SLE, clearance of

Table 1. Clinical features of 6 male patients based on the American College of Rheumatology revised criteria for $\mathrm{SLE}^{6}$. Hematologic abnormalities defined as leukopenia (white blood cells $<4,000 \mathrm{cells} / \mathrm{mm}^{3}$ ), lymphopenia (lymphocytes $<1,500 \mathrm{cells} / \mathrm{mm}^{3}$ ), anemia (hemoglobin $<14 \mathrm{~g} / \mathrm{dl}$ ), and/or thrombocytopenia (platelet count $<400,000$ cells $/ \mathrm{mm}^{3}$ ) more than once and not explained by other diseases or drug use.

\begin{tabular}{|c|c|c|c|c|c|c|}
\hline & \multicolumn{6}{|c|}{ Patient } \\
\hline & 1 & 2 & 3 & 4 & 5 & 6 \\
\hline Current age, yrs & 25 & 42 & 38 & 45 & 37 & 31 \\
\hline Age at diagnosis, yrs & 21 & 30 & 26 & 41 & 34 & 23 \\
\hline Ethnicity & $\mathrm{H}$ & $\mathrm{AA}$ & $\mathrm{H}$ & AA & $\mathrm{AA}$ & $\mathrm{H}$ \\
\hline Malar rash & - & - & + & - & - & - \\
\hline Photosensitivity & - & + & - & - & + & + \\
\hline Discoid lupus & - & - & - & + & + & - \\
\hline Oral ulcers & + & + & + & - & + & + \\
\hline Serositis & + & + & + & - & + & + \\
\hline Arthritis & + & + & + & - & + & + \\
\hline Renal involvement & + & + & + & - & + & + \\
\hline CNS involvement & + & - & + & - & - & - \\
\hline \multicolumn{7}{|c|}{ Hematologic abnormalities } \\
\hline Leukopenia & - & + & - & + & + & - \\
\hline Lymphopenia & + & + & + & + & + & + \\
\hline Anemia & + & + & - & + & + & + \\
\hline Thrombocytopenia & - & + & - & + & + & + \\
\hline \multicolumn{7}{|l|}{ Antibodies } \\
\hline Anti-Smith & - & - & - & + & - & - \\
\hline Anti-RNP & - & - & - & + & + & + \\
\hline Anti-Ro/La & $-1-$ & $+/-$ & $-1-$ & $-1-$ & $-1-$ & $-1-$ \\
\hline Anti-dsDNA & + & + & + & - & + & - \\
\hline Anticardiolipin & + & - & + & - & - & - \\
\hline LAC & - & - & + & - & - & - \\
\hline ANA & + & + & + & + & + & + \\
\hline
\end{tabular}

H: Hispanic, AA: African American; CNS: central nervous system; LAC: lupus anticoagulant; ANA: antinuclear antibodies. 
apoptotic cells ${ }^{8}$ is impaired, with accumulation of agonal cells in various tissues. During apoptosis there is formation of blebs on the cell surface, exposing antigens that are normally intracellular. Inadequate clearance of these self-antigens (e.g., nuclear antigens) plays a major role in autoimmunity 9 .

Cocaine influences discrete responses in different cell types. In neutrophils, cocaine inhibits ligand/receptor-dependent release of reactive oxygen species (ROS), blocks upregulations of CR3 (impairing neutrophil aggregation/adhesion to vascular endothelium), and interferes with phagocytosis and membrane fluidity. Cocaine also decreases extracellular secretion of lysosomal enzymes, beta-glucuronidase, and lysozyme ${ }^{10,11}$, decreasing phagocytosis by alveolar macrophages ${ }^{12}$.

In non-professional phagocytes, e.g., epithelial cells ${ }^{13}$, cardiocytes $^{14}$, and cortical neurons ${ }^{15}$, cocaine induces apoptosis. Dey and Snow found that embryonic locus coeruleus neurons undergo apoptosis after cocaine exposure $^{16}$. The effect is mediated by tumor necrosis factor- $\alpha$, with upregulation of Bax protein and activation of caspase- 9 and downstream caspase- $3^{16}$. In general, apoptotic blebs are opsonized by complement or phosphatidylserine (PS) expression (through flippases) on the apoptotic cell membrane. C3 and PS are ligands for receptor-mediated phagocytosis and removal $^{8}$. Professional phagocytes contribute to resolution of inflammation by clearance of proinflammatory cellular debris after programmed cellular death. In SLE, neutrophils phagocytose apoptotic cells via discrete ligand/receptor signals; their ingestion of IgG-opsonized nuclei was first recognized as the LE cell ${ }^{17,18}$.

Therefore, cocaine, by increasing apoptosis and impairing phagocytosis, could permit excess presentation of undigested bleb residues to dendritic cells. This process would lead to Fc-gamma receptor-mediated phagocytosis of apoptotic material with initiation of autoreactivity by dendritic cell maturation and production of inflammatory cytokines through Toll-like receptor signaling 8,19 .

It is reasonable to consider the development of autoimmunity, including SLE, especially in males, as an additional risk with cocaine abuse. Additionally, because numerous health issues are associated with cocaine exposure, consideration is recommended of the social history of male patients with lupus related to recreational drugs, specifically cocaine.

TANIA L. RIVERA, MD; H. MICHAEL BELMONT, MD; GERALD WEISSMANN, MD, New York University School of Medicine, New York, New York, USA. Address correspondence to Dr. T.L. Rivera, Department of Medicine, Division of Rheumatology, New York University School of Medicine, 301 East 17th Street, Room 1410, New York, NY 10003.

E-mail: tania.rivera@nyumc.org.

\section{REFERENCES}

1. Soto ME, Vallejo M, Guillén F, Simón JA, Arena E, Reyes PA. Gender impact in systemic lupus erythematosus. Clin Exp Rheumatol 2004;22:713-21.

2. Lahita RG. The role of sex hormones in systemic lupus erythematosus. Curr Opin Rheumatol 1999;11:352-6.

3. Sanchez-Guerrero J, Villegas A, Mendoza-Fuentes A, Romero-Díaz J, Moreno-Coutiño G, Cravioto MC. Disease activity during the premenopausal and postmenopausal periods in women with systemic lupus erythematosus. Am J Med 2001;111:464-8.
4. Friedman H, Pross S, Klein TW. Addictive drugs and their relationship with infectious diseases. FEMS Immunol Med Microbiol 2006;47:330-42.

5. Hymes KB, Cheung T, Greene JB, Prose NS, Marcus A, Ballard H, et al. Kaposi's sarcoma in homosexual men - a report of eight cases. Lancet 1981;2:598-600.

6. Hochberg MC. Updating the American College of Rheumatology revised criteria for the classification of systemic lupus erythematosus [letter]. Arthritis Rheum 1997;40:1725

7. Galanter M, Egelko S, De Leon G, Rohrs C, Franco H. Crack/cocaine abusers in the general hospital: assessment and initiation of care. Am J Psychiatry 1992;149:810-5.

8. Cohen PL. Apoptotic cell death and lupus. Springer Semin Immunopathol 2006;28:145-52.

9. Casciola-Rosen LA, Anhalt G, Rosen A. Autoantigens targeted in systemic lupus erythematosus are clustered in two populations of surface structures on apoptotic keratinocytes. J Exp Med 1994;179:1317-30.

10. Haines KA, Reibman J, Callegari PE, Abramson SB, Philips MR, Weissmann G. Cocaine and its derivatives blunt neutrophil functions without influencing phosphorylation of a 47-kilodalton component of the reduced nicotinamide-adenine dinucleotide phosphate oxidase. J Immunol 1990;144:4757-64.

11. Mukunda BN, Callahan JM, Hobbs MS, West BC. Cocaine inhibits human neutrophil phagocytosis and phagolysosomal acidification in vitro. Immunopharmacol Immunotoxicol 2000;22:373-86.

12. Baldwin GC, Tashkin DP, Buckley DM, Park AN, Dubinett SM, Roth MD. Marijuana and cocaine impair alveolar macrophage function and cytokine production. Am J Respir Crit Care Med 1997;156:1606-13.

13. Trimarchi M, Miluzio A, Nicolai P, Morassi ML, Bussi M, Marchisio PC. Massive apoptosis erodes nasal mucosa of cocaine abusers. Am J Rhinol 2006;20:160-4.

14. Iacobellis G, Kemp W. Cardiomyocyte apoptosis in cocaine-induced myocarditis with involvement of bundle of His and left bundle branch. Int J Cardiol 2006;112:116-8.

15. Nassogne MC, Louahed J, Evrard P, Courtoy PJ. Cocaine induces apoptosis in cortical neurons of fetal mice. J Neurochem 1997;68:2442-50.

16. Dey $\mathrm{S}$, Snow DM. Cocaine exposure in vitro induces apoptosis in fetal locus coeruleus neurons through TNF-alpha-mediated induction of Bax and phosphorylated c-Jun $\mathrm{NH}(2)$-terminal kinase. J Neurochem 2007;103:542-56.

17. Hepburn AL. The LE cell. Rheumatology 2001;40:826-7.

18. Schmidt-Acevedo S, Pérez-Romano B, Ruiz-Argüelles A. 'LE cells' result from phagocytosis of apoptotic bodies induced by antinuclear antibodies. J Autoimmun 2000;15:15-20.

19. Frisoni L, McPhie L, Colonna L, Sriram U, Monestier M, Gallucci $\mathrm{S}$, et al. Nuclear autoantigen translocation and autoantibody opsonization lead to increased dendritic cell phagocytosis and presentation of nuclear antigens: a novel pathogenic pathway for autoimmunity? J Immunol 2005;175:2692-701.

J Rheumatol 2009;36:12; doi:10.3899/jrheum.090271 